\title{
Research on a Special Welding Robot for Earphone Plug
}

\author{
Y.X. WANG, W.Z. YU, Z.D. WANG, H.T. FANG \& K. HE \\ Shenzhen Institutes of Advanced Technology, Chinese Academy of Sciences, Shenzhen, China \\ Shenzhen Key Laboratory of Precision Engineering
}

R.X. DU

The Chinese University of Hong Kong, Hong Kong

\begin{abstract}
In order to realize automatic welding of earphone plug, this paper analyzed the current welding process, and developed a special automatic welding robot for earphone plug. The robot was based on rectangular coordinate manipulator, which was driven by stepper motors and integrated the functionality of automatic cutting, automatic dipping tin, automatic feeding, and automatic welding. The robot was simple to operate. It used PLC as core control system and a touch screen for human-computer interface. The experiments proved the robot to be efficient, stable and reliable for earphone plug welding and it was environmental friendly.
\end{abstract}

KEYWORD: Welding robot; Earphone plug; Special shaped columns; Welding process; PLC control system

\section{INTRODUCTION}

With the development of science and technology, various industrial robots and automated equipments are developed to help workers to finish some monotonous, repeated and long-time work. In addition, they also play a very important role on improving the production efficiency, ensuring product reliability, and reducing the product defective percentage.

As a global manufacturing country, China has many electronic components manufacturer. As traditional labor-intensive industry, automatic welding technology [1-2] has not been mature enough. Current automatic welding equipments are mainly for USB plugs, DC plugs and PCB boards [3]. However, there are few studies on automatic welding robot for welding special-shaped columns like earphone plug, as shown in Figure 1, and there is no similar product on the market.

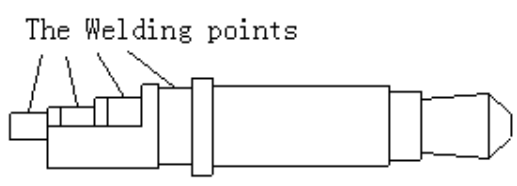

Figure 1. Illustration of earphone plug

As a typical special-shaped column, the welding process of earphone with enameled wire need multiple procedures, which in order are cabling, trimming, polishing, tin dipping, welding and testing, etc. With these procedures, the factories can produce 2000 3000 earphones per day. It is obviously that the welding process has the problems such as low degree of automation, low production efficiency and many complicated procedures. The welding procedure is especially critical for operator's skill and they will inhale large amount of harmful gas in the long working time. Thus, it is especially necessary to develop an automatic robot for earphone plug welding.

This paper studied the automatic welding technology, and proposed a design of the automatic welding robot's mechanical structure and control system for the earphone plug welding. At last, the feasibility of the design was proved by the experimental results.

\section{RESEARCH OF AUTOMATIC WELDING}

\subsection{Current Welding Process}

The current earphone plug welding process is shown in Figure 2. First, the workers assemble the terminals' parts, and inject to mold the terminals. Then, workers manually polish the welding points on the plugs to ensure the tin can cling to the welding points effectively. The welding points include the left ear point, the right ear point, the microphone point, and the ground wire point. Meanwhile, they strip the enameled wire's jacket, and leave the varnished wires. And then they trim the varnished wires and dip them in tin. At last, workers weld the polished terminals with treated varnished wires and inject them to mold again. 


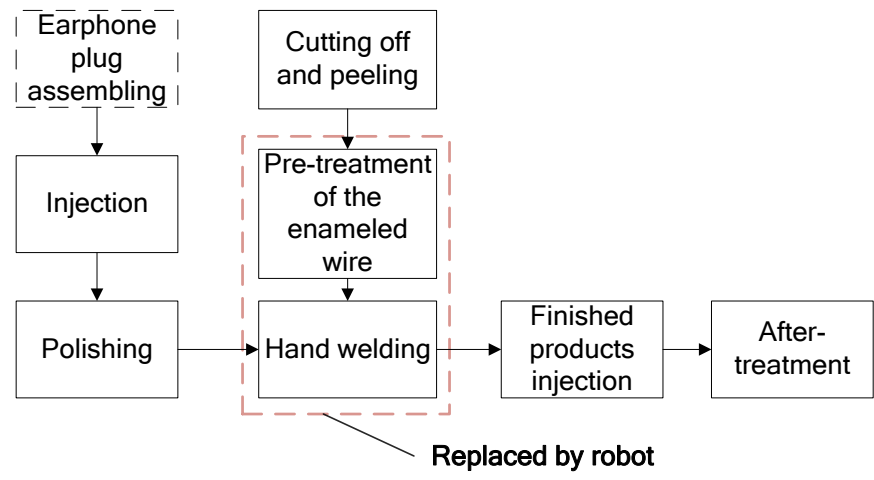

Figure 2. The earphone plug welding proces

\subsection{Project Objective}

Considering the key problems in the earphone plug welding process, base on PLC control, we designed a special welding robot. It could solve all the key problems, such as laying the enameled wires, loading the parts, welding the earphone plug with varnished wires, and it also deal with other procedures. Low cost and high reliability was the ultimate goal of automatic welding robot.

The procedure of laying flexible cables was still been done by manual operation because it was a high challenge for robot. The workers fixed four cables through special clamping apparatus, and then the cables were trimmed, dipped in tin, moved to the welding station. After preliminary screening by vibration plate, the earphone terminals entered into the designated channel. The surface characteristics were identified by sensors and motors to determine the direction of the welded surface. Welding cables and the terminal moving to the welding station rely on specialized jigs to complete welding.

\section{ROBOT'S STRUCTURE DESIGN}

The structure of the automatic welding robot is shown in Figure 3. It mainly consisted of terminal identification module, rotated parts feeding module, welding module, tin dipping module, wire trimming module, wire feeding module and control device.

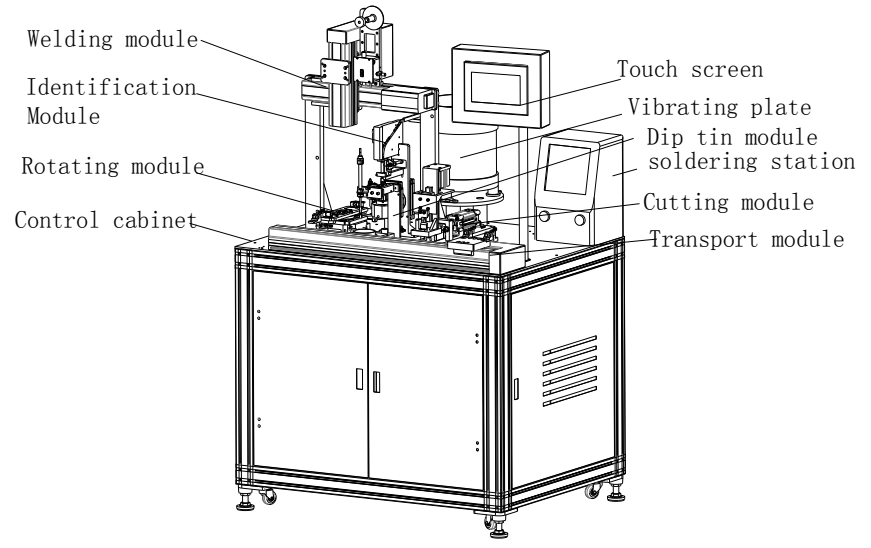

Figure 3 . The whole structure of the automatic welding robot

\subsection{Identification Module and Rotating Module}

It can be seen from Figure 4 that the terminal entered the slide through the vibration tray, and then the air cylinder clamped the falling terminals. By the high precision optical fiber sensor, the welding plane could be detected on the rotating terminal driven by motor. After detection, the terminal was absorbed by vacuum and sent to the welding position. The turntable was driven by $180^{\circ}$ rotating cylinder to achieve double location which could be identified and welded simultaneously, so it was time saving and cost effective. Some external mechanical assisted positioning device was designed to ensure the rotational accuracy of recognition module and rotating module.

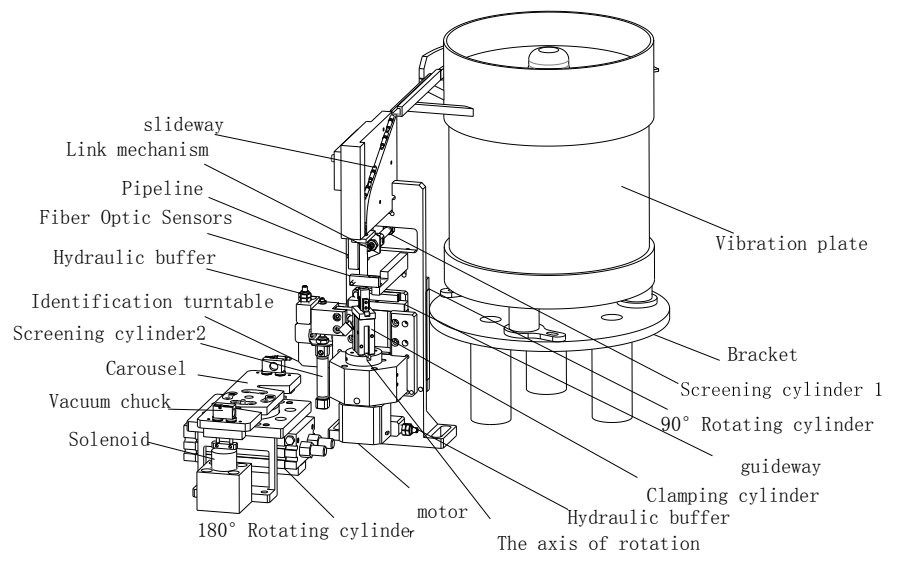

Figure 4. Identification module and rotating module

\subsection{Welding Module}

Considering control convenience and cost, rectangular coordinate mechanical arm was chosen to build a 3-axis platform to complete the welding process. Its structure is shown in Figure 5. Its two screw rods were towards different directions, and derived soldering iron group to move along $\mathrm{X}$ and $\mathrm{Y}$ directions. The step motors were driven by synchronous belt, which was effective to reduce the impact of stops and starts and to prevent overload caused by losing step. In addition, the lead screw chose lead of $5 \mathrm{~mm}$, and had a self-locked function to prevent the gravity drop.

\subsection{Transport Module}

The earphones cable sheath was $3 \mathrm{~mm}$ in diameter, and welding wire diameter was $0.3 \mathrm{~mm}$. The distances between the four welding joints on terminal were respectively $2 \mathrm{~mm}, 1.5 \mathrm{~mm}$, and 1.5 $\mathrm{mm}$. The wire card components were fixed side by side on the removable mobile plate, which ensured much more numbers of earphones welding. The mobile plate was fixed on the lead screw sliders. All these structures and operations guaranteed a smooth, reliable machining process, lower cost and less work time. The structure of the transport module is shown in Figure 6. 


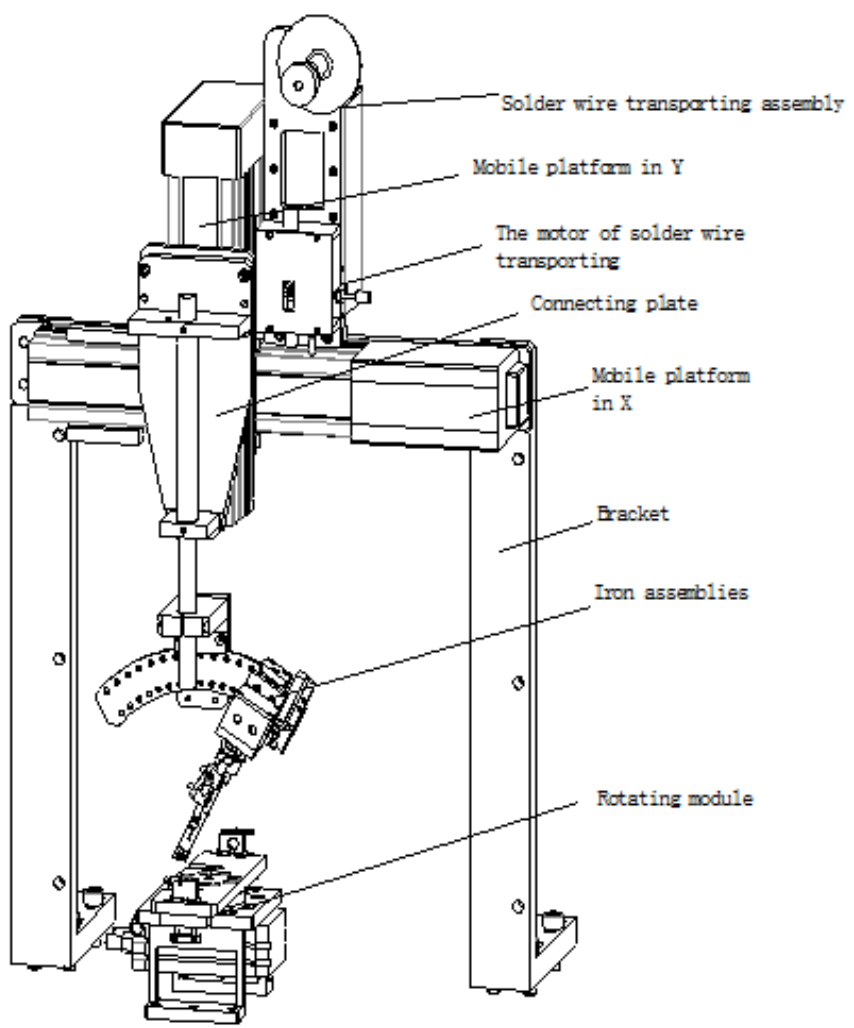

Figure 5. Welding module

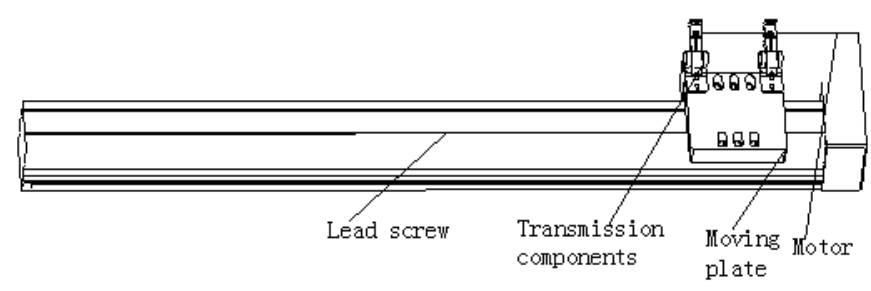

Figure 6. Transport module

\subsection{Cutting Module and Tin Dipping Module}

The enameled wire pre-treating process included trimming and tin dipping. In order to control simply and reduce cost, air cylinder driven was applied in dipping and trimming operations. When the wires were sent to the trimming position, trimming started under the control of electromagnetic valve controller. After trimming, the wires were sent by the wire feeding module to the dipping position, and the air cylinder for tin dipping started working to make wire card components rotate $90^{\circ}$ for tin dipping in the welding machine. Cutting module and tin dipping module is shown in Figure 7.

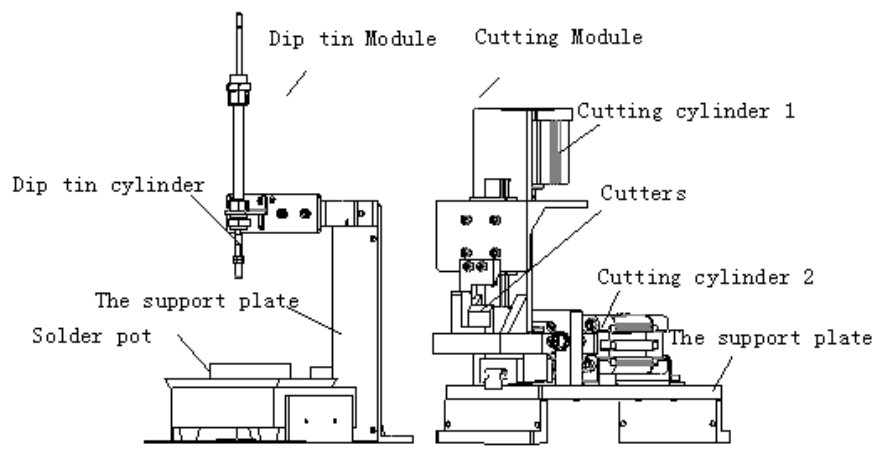

Figure 7. Cutting module and tin dipping module

\section{CONTROL SYSTEM DESIGN}

\subsection{Hardware Design}

According to control objective of the welding robot, the designed machine chose Panasonic AFPX-C60T PLC. The control system structure is shown in Figure 8. The modular structure was applied in PLC control system to meet maximum performance requirement. The PLC control system realized the system configuration, logical control, sequential control, interconnected control and PID regulation. System appearance was small in size, but cost efficient and could work reliably in bad environment. PLC system installation and configuration was simple, and suitable for all kinds of installation environment.

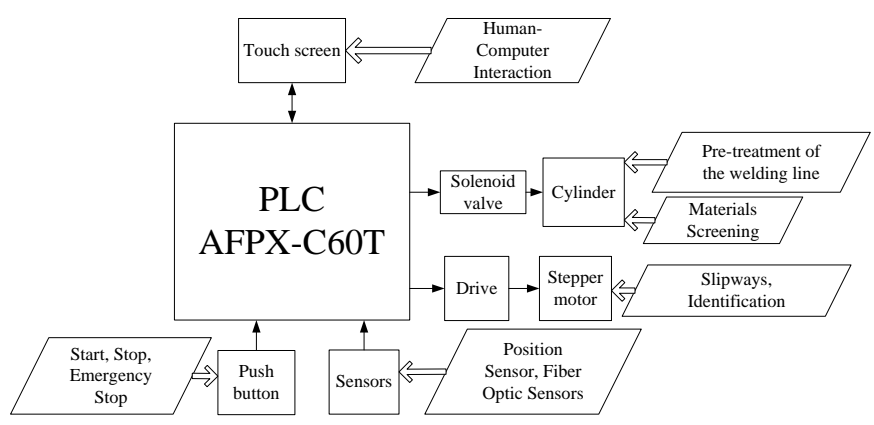

Figure 8. Control system structure

\subsection{Software Design}

Main program mainly included manual operations module, automatic operations module and parameters adjustment module. We could run the executive component by single step for debugging. In automatic operations module, the earphone plug identification process of the material and enameled wire was a concurrent design, which improved the production efficiency. Parameter adjustment module could adjust the kinetic parameters of components according to the actual need. The automatic welding robot control flow chart is shown in Figure 9.

\section{EXPERIMENTAL RESULTS}

According to the design and implementation scheme, we successfully developed a prototype and carried out an earphones welding experiment in a factory. The experimental results had been compared with the manual welding results, which are shown in the Table 1. From the table, it proved that the welding results by robot were better, which had a higher product pass percent. And also the robot improved production efficiency and work environment. 


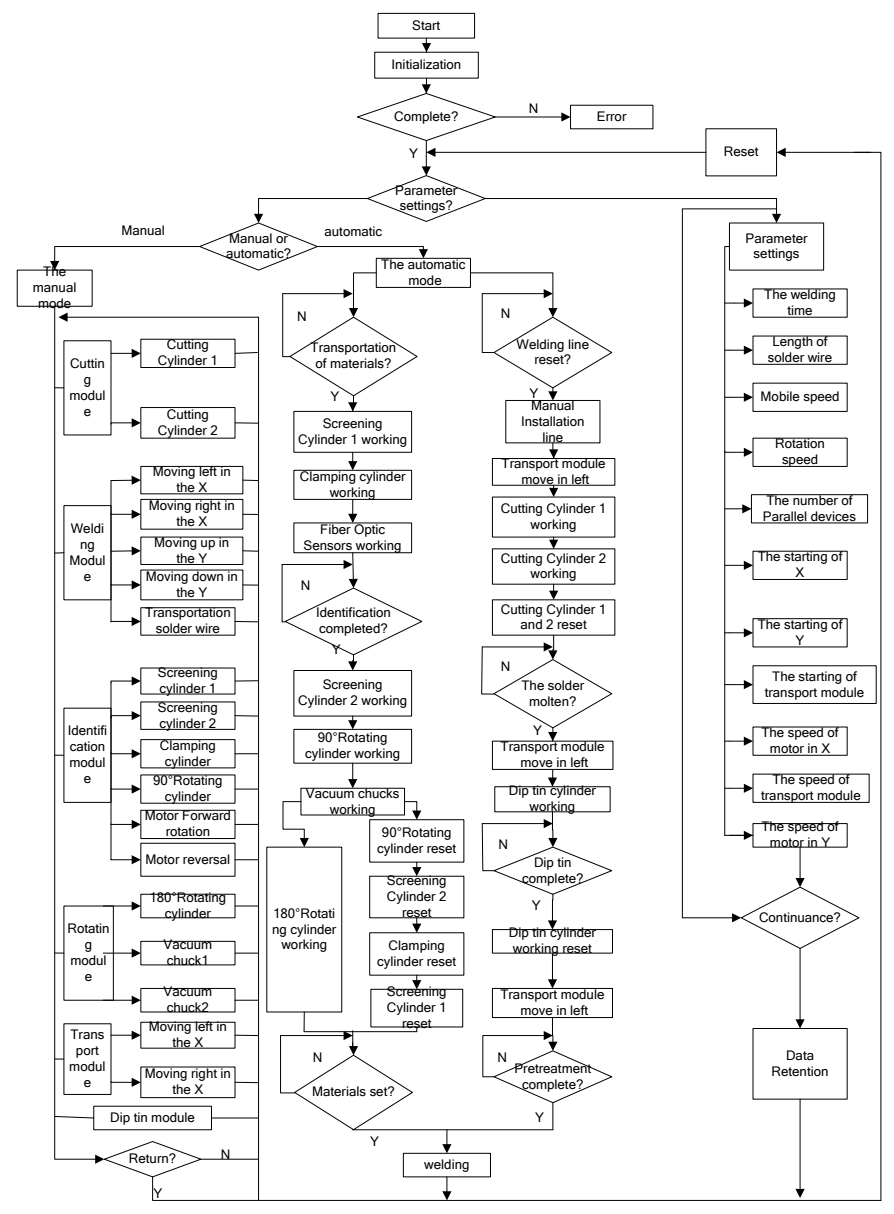

Figure 9. Software structure

Table 1. Comparison of manual welding and robotic welding

\begin{tabular}{|l|l|l|}
\hline & Manual welding & Robotic welding \\
\hline Average output & $2500-3000 /$ day & $5500-6000 /$ day \\
\hline Working time & 8 hours & 8 hours \\
\hline Passing rate & $90 \%$ & $97 \%$ \\
\hline $\begin{array}{l}\text { Working } \\
\text { environment }\end{array}$ & $\begin{array}{l}\text { Workers inhale toxic } \\
\text { leaded gas. }\end{array}$ & $\begin{array}{l}\text { Toxic gas is } \\
\text { effectively collected. }\end{array}$ \\
\hline Workload & $\begin{array}{l}\text { Heavy task and high } \\
\text { technical } \\
\text { requirements. }\end{array}$ & $\begin{array}{l}\text { Simple tasks and low } \\
\text { technical } \\
\text { requirements. }\end{array}$ \\
\hline
\end{tabular}

\section{CONCLUSIONS}

This paper studied the design method, structure, and control system of the special welding robot for special-shape column earphone plugs, and successfully developed a prototype machine. The welding robot adopted a rectangular coordinate manipulator which was driven by stepping motor to reduce the cost and meet the welding requirement. From the perspective of waste gas purification and waste recycle, it not only improved the working environment but also reduced the pollution. In addition, double position design was adopted in the rotated feeding process to improve production efficiency. The successful research on the special welding robot for the earphone plugs laid the foundation for further study

\section{ACKNOWLEDGEMENT}

This work was supported by "Guangdong Introduced Leading Talents" project, Shenzhen Basic Research Project "Mechanism and experiment study on incremental sheet metal forming using high pressure water jet" (project no: JCYJ20120615140848467). The authors would like to thank the supports very much.

\section{REFERENCES}

[1] Lin, S.Y. 2005. Present Situation of Welding Production and Development Trend of Welding Technology in China. Ship Engineering. Supplement (27): 15-24.

[2] Hu, L.F. 2014. Current production and development of Chinese welding technology. Technology development of enterprise. 33(32):12-13.

[3] Wang, J.T. 2013. Automatic welding system for Seam based on PLC control. Shandong University. Master thesis. 